\title{
Using IPEC pedagogy to transform the future rural advanced practice nursing workforce
}

\author{
Kelly D. Rosenberger*1, Heidi Olson², Martin MacDowell ${ }^{3}$, Valerie Gruss ${ }^{4}$ \\ ${ }^{1}$ Department of Human Development Nursing Science, University of Illinois Chicago, UIC Health Sciences Campus in Rockford, \\ United States \\ ${ }^{2}$ College of Pharmacy, University of Illinois-Chicago, UIC Health Sciences Campus, Rockford, Illinois, United States \\ ${ }^{3}$ College of Medicine, University of Illinois-Chicago, UIC Health Sciences Campus, Rockford, Illinois, United States \\ ${ }^{4}$ Department of Biobehavorial Nursing Science, College of Nursing, University of Illinois - Chicago, Chicago, Illinois, United \\ States
}

Received: March 10, 2021

DOI: $10.5430 /$ jnep.v11n10p1
Accepted: May 18, 2021

Online Published: May 26, 2021

\begin{abstract}
Objective: The number of primary care providers has not kept pace with the increasing number of underserved rural populations placing unprecedented demands on the healthcare system and the gap is expected to widen with shortages projected to increase across the United States. Given the urgent need to grow and expand the number of trained diverse primary care providers in rural communities, an innovative sustainable program was implemented to recruit and train diverse rural advanced practice nurses. Building on the successful rural medical and rural pharmacy educational programs at the UIC Health Sciences Campus in Rockford, a rural nursing program with interprofessional curriculum was designed and refined to enable nursing students along with two other professions to develop appreciation, insight, and knowledge of rural healthcare and health disparities in a variety of rural settings as part of an interprofessional team.

Methods: A mixed-methods program evaluation approach utilized both quantitative and qualitative data to evaluate program satisfaction and inform ongoing program refinement.

Results: Students indicated positive responses to this interprofessional course of study. Continued development and refinement of the curriculum is planned to train the future rural healthcare workforce.

Conclusions: Students from three health sciences colleges benefitted from the IPEC program with confirmed satisfaction in interprofessional rural education and collaborative practice. The addition of a rural nursing program merits continuation with modification and expansion to prepare the future rural interprofessional healthcare workforce.
\end{abstract}

Key Words: Rural nursing, Interprofessional education, Community-engaging learning, Collaborative practice, Health disparities

\section{INTRODUCTION}

The number of primary care providers has not kept pace with the growing number of underserved rural populations placing unprecedented demands on the healthcare system and the gap is expected to widen with shortages projected to increase across the USA by $2025 .{ }^{[1]}$ Simultaneously, underserved rural populations are becoming more racially and ethnically diverse while the rural healthcare workforce lacks

\footnotetext{
* Correspondence: Kelly D. Rosenberger; Email: kellyr@uic.edu; Address: Department of Human Development Nursing Science, University of Illinois Chicago, UIC Health Sciences Campus in Rockford, United States. 
diversity. ${ }^{[2]}$ Healthcare providers who themselves come from diverse rural backgrounds are more likely to practice in low resourced settings and individuals who receive care from healthcare providers who are similar in background experience better healthcare outcomes.

Given the urgent need to increase and expand the number of trained multidisciplinary primary care providers in rural communities, an innovative sustainable rural nursing program was implemented to recruit and train diverse rural advanced practice nurses. Building on the successful rural medical (RMED) and rural pharmacy (RPHARM) education programs at the University of Illinois - Chicago (UIC) Health Sciences Campus in Rockford, a rural nursing program with interprofessional curriculum was designed and refined to enable nursing students along with the RMED and RPHARM students to develop appreciation, insight, and knowledge of rural healthcare and health disparities in a variety of rural settings as part of an interprofessional (IP) team.

The longitudinal interprofessional curriculum includes didactic and experiential learning activities over a four-year period. The overarching program objectives enable learners to utilize family and patient-centered methods to focus on healthcare disparities in rural populations; describe issues and factors affecting rural healthcare and identify new policies and approaches for addressing the needs of rural populations; define the four domains of the Interprofessional Education Collaborative (IPEC) core competencies; and apply the IPEC competencies as an interprofessional team in a rural community.

This manuscript describes the curriculum and evaluation results from the early years of the Rural Nursing Concentration known as the RNURSING Program. The longitudinal, interprofessional curriculum was provided in a hybrid format with pre-and-post online activities, synchronous collaborative meetings, and experiential learning activities in rural communities guided by IP faculty and established rural partners. The program content included key reading materials, learning modules, and videos. Throughout the initial years of the RNURSING Program, multidisciplinary students spent one evening a month together for didactic learning and 1-2 days together at a variety of established community settings for experiential learning each semester. The didactic and experiential learning activities together address the gamut of rural healthcare issues across the lifespan. The group sessions were guided by the IP faculty and included individual student reflection as well as both small and large group discussions. The community activities were guided by IP faculty and rural collaborators offering a wide array of healthcare experiences in diverse rural settings. The basic structure of the IPEC program has been maintained virtually using Zoom meetings and breakout sessions during the COVID-19 pandemic when in-person classes and events were cancelled.

Learners from three healthcare professions in the College of Nursing (CON), College of Medicine (COM), and College of Pharmacy (COP) were eligible to apply to the RNURSING, RMED and RPHARM programs, respectively. Collectively, the three programs are referred to as the Rural Health Professions Programs (RHP).

IP course faculty and other faculty and staff associated with the UIC Health Sciences Campus in Rockford reviewed applications and selected students for admission to the three programs. The Rural Health Professions Programs were tailored to the three health sciences professions and could be modified to include other healthcare professional students.

The participants discussed in this manuscript were from four cohorts of the three health science colleges enrolled in the RHP programs in academic years (AY) 2017, 2018, 2019, and 2020. The background and demographic information of students entering the RHP Program by AY 2017-2020 is presented in Table 1.

Table 2 lists the specific learning objectives for each of the RNURSING semesters. Included with each activity, were objectives aligned with the assigned subject matter and the IPEC competencies. The RHP students were provided educational activities to develop rural healthcare competencies, team-based care competencies, and mentored in developing and implementing community projects, presentations, and manuscripts.

\subsection{Theoretical framework}

The program objectives and activities were designed utilizing adult learning principles to foster active learning and included reflective strategies. ${ }^{[3]}$ A transformative learning model was the basis of the experiential learning activities for students to develop proficiency and interprofessional team competencies while applying ethical conduct and engaging in critical thinking. ${ }^{[3]}$ Transformational learning consists of several fundamental changes: away from memorization of facts to searching for, analysis of, and conceptualization of information for decision making; away from seeking professional credentials to achieving competencies for effective teamwork in healthcare systems; and away from standard educational models to creative adaptation of global and local resources to meet the priority needs. ${ }^{[4]}$

\subsection{Didactic content}

Didactic content included synchronous course sessions as well as asynchronous online course materials and modules. 
The program materials were available for students via the Blackboard Learning Management System and the electronic course sites included the course syllabi, course schedule, IP faculty contact information, learning objectives, assignments, readings, videos, discussion board, and resources.
The course content was collaboratively developed by the IP rural faculty and the rural partners, who also accompanied the learners to the institutions in rural communities, facilitating learning during the course activities.

Table 1. Demographics and background information of students entering into rural health professions program by academic year 2017-2020

\begin{tabular}{|c|c|c|c|c|}
\hline & 2017-18(Class 2021) & 2018-19(Class 2022) & 2019-20(Class 2023) & 2020-21 (Class 2024) \\
\hline \multicolumn{5}{|c|}{ Rural Residential Background } \\
\hline Yes & 26 & 20 & 27 & 21 \\
\hline No & 14 & 16 & 10 & 10 \\
\hline \multicolumn{5}{|l|}{ Gender } \\
\hline Female & 22 & 17 & 27 & 17 \\
\hline Male & 18 & 19 & 10 & 14 \\
\hline \multicolumn{5}{|l|}{ Racial Background } \\
\hline Asian & 2 & 0 & 2 & 2 \\
\hline African American & 1 & 1 & 0 & 1 \\
\hline Caucasian & 34 & 34 & 33 & 28 \\
\hline Multi-Racial/Other & 3 & 1 & 2 & 0 \\
\hline \multicolumn{5}{|l|}{ Hispanic/Latino } \\
\hline Yes & 2 & 3 & 1 & 0 \\
\hline No & 38 & 33 & 36 & 31 \\
\hline \multicolumn{5}{|l|}{ Profession } \\
\hline Medicine & 22 & 24 & 29 & 24 \\
\hline Nursing & 6 & 7 & 4 & 6 \\
\hline Pharmacy & 12 & 5 & 4 & 1 \\
\hline
\end{tabular}

\subsection{Experiential content}

Experiential learning activities were developed and directed in collaboration with rural community-based partner organizations (Dairy Farm, Farm Hazard \& Safety Simulation, Rural Critical Access Hospitals, Rural Long-Term Care Pharmacy, Rural Healthcare Clinic, Rural Hospice Agency, Rural County Health Department, Disability Assistance Agency, Rural Family Counseling Center, Rural Senior Center, Drug Rehabilitation Center). The community-based partners were across diverse settings offering students opportunities to interact with rural populations and healthcare professionals at a variety of locations providing rural healthcare services. The robust diversity of the rural community settings combined with the clinical expertise of the practicing interprofessional teams delivered high-quality learning experiences. Additionally, students had clinical case simulation opportunities, standardized patient simulations, development, and implementation of an educational activity for elementary school students, team building activities, shadowing assignments, and reflection activities. Learners were able to partake in learning activities focusing on ethical family and patientcentered rural healthcare issues. Together, the didactic and experiential curriculum prepare students to practice in and care for diverse rural populations. Exposing the IP students Published by Sciedu Press to underserved rural communities contributed to the students' contextualization of the determinants of health.

\subsection{Scholarship}

During the longitudinal course of study, the students selected a scholarly topic related to rural healthcare for development, implementation, evaluation, and dissemination of their rural community-oriented research, evidenced-based practice, or quality improvement project. The students presented their projects at the annual IPE research event during their last course before graduation.

\section{Methods}

Utilizing the evaluation model by Kirkpatrick, ${ }^{[5]}$ the authors examined the RHP program curriculum's impact on students' reactions (satisfaction) with a mixed-methods evaluation survey to inform ongoing program improvements. Data collected included online quantitative survey data measuring overall quality of the course and qualitative survey data (each activity, each course, and overall program evaluation surveys) of the students' experience. A mixed-methods approach was utilized with online quantitative surveys assessing the students' program satisfaction and measuring if the objectives were met with a standard course evaluation scale: 5 
(Excellent) to 1 (Poor), * indicates no results due to low response rates. Additionally, each spring semester beginning in 2017, the authors sent out IRB-approved IPEC surveys that included the Interprofessional Collaborative Competency Attainment Survey (ICCAS) and the Interprofessional Education Collaborative Competency Self Efficacy Tool (IPECCSET 38) to all students in COM, CON, and COP at the UIC Health Sciences Campus in Rockford as well as the students in the Rural Nursing Program from the 5 other CON Campuses. The ICCAS utilizes a retrospective approach with a 20 -item self-report tool designed to assess skills in collaboration, communication, roles/responsibilities, conflict management/resolution, collaborative patient-family centered approach, and team functioning. ${ }^{[6,7]}$ The ICCAS tool is a valid tool with high internal consistency allowing IPE programs to evaluate effectiveness while the participants have the opportunity to reflect on their IPEC competencies. ${ }^{[6,7]}$ The original IPECC-SET 38 tool was condensed to IPECC-SET 9 upon analysis for measuring perceived self-efficacy for interprofessional collaborative practice competence. ${ }^{[8]}$ Items 1 to 4 included with the IPECC-SET survey and the ICCAS were originally designed to allow the authors to match the students' responses across the years of being in RHP to compare their responses from each year.

\section{RESUlts}

The results of the IRB approved IPECC-SET 9 survey included responses for 2 academic years as seen in Table 3 . The NURSING response rate (n) for year 1 was 19 and the response rate (n) for Year 2 was 4.

Table 4 provides the overall course evaluations ranging from 4 to 5 for the rural nursing students. Online qualitative survey data obtained from all three disciplines of students participating in RHP was grouped by theme with too low of a response rate for descriptive analysis. Table 5 includes examples of qualitative survey responses after each activity, each course, and end of program evaluation. Since the IP RHP faculty conducted their own online surveys after each course activity, the students often did not complete the endof-semester course evaluations. The low response rate of the end-of-semester quantitative survey is most likely due to the students' having already completed the online surveys after each of the RHP course activities. Additionally, adding to the complexity of the end-of-semester course evaluation results, the Colleges of Medicine, Nursing, and Pharmacy utilize different course evaluation systems for all courses within each of the three colleges. While the authors noted a $56 \%$ attrition rate amongst the rural nursing students as discussed further in the limitations section, overall, they are inspired by the positive responses from the students in Tables
4 and 5 to this interprofessional course of study and plan to continue modifying and refining the curriculum to train the future rural IP healthcare workforce.

\section{Discussion}

The IRB-approved IPEC survey that included the ICCAS tool unfortunately did not provide adequate data for the authors to analyze. The authors discovered a data problem with only one RHP student who matched and answered questions across all 4 years in 2018, 2019, 2020, and 2021. Thus, trying to compare means between the years with different students answering the questions would not work. Additionally, there were 40, 36, 37, and 31 students entering into RHP per year since 2017 in years 1, 2, 3, and 4 respectively, and if all students completed the surveys each of the 4 years there should have been approximately 373 responses. There were only 11 responses in 2018, 33 in 2019, 1 in 2020, and 19 in 2021 for a total of 64 responses. Thus, the authors discovered another data issue with a very low response rate (17\%) on top of the matching issue (different students responding) confounding the data problem. Regarding the IPECC-SET 9 data in Table 3 , the authors acknowledge the limitations of the data due to the small number of responses from the nursing students as well as the inability to match the students' responses over time and conclude the validity of the $t$-tests is very weak.

The course evaluation results have led to program modifications including enhancing course activities in which the students provided constructive comments. The first session in year one, for example, was enhanced to include real-life practicing interprofessional guest speakers from all three professions. Another example included replacing an in-class session with an online asynchronous activity as requested by the students. Based on the most recent qualitative feedback from students, plans are underway to revise the format and course sequencing of the Health Jam activities. The curriculum topics are continually updated to include content relevant to real life circumstances such as COVID-19 in rural populations.

Training and increasing the healthcare workforce to deliver effective and inclusive family and patient-centered care for rural populations is a nationwide priority. The RHP Programs (RMED, RNURSING, and RPHARM) cultivate RHP learners' ability to provide inclusive family and patient-centered care as teams and to become advocates and leaders to enhance the well-being and health of rural populations. Data from the evaluation of the RHP Programs offers evidence the didactic and experiential learning experiences successfully met the course objectives and satisfied the students while preparing them to be able to provide high-quality IP healthcare for rural populations. 
Table 2. Rural nursing course program objectives by semester and year

\begin{tabular}{|c|c|}
\hline Course/Semester/Year & Objectives \\
\hline $\begin{array}{l}\text { Rural Family \& Community Healthcare I } \\
\text { Fall Semester - Year } 1\end{array}$ & $\begin{array}{l}\text { Upon completion, students will: } \\
\text { 1. Distinguish and compare ways rural health professionals interact with their communities to enhance health; } \\
\text { including socio-cultural awareness in patient care, informed and appropriate use of rural community health } \\
\text { resources, and rural community involvement and attachment. } \\
\text { 2. Apply the core concepts underlying the specialty of family healthcare, including holistic patient care, family } \\
\text { context, continuity of care, patient/family education, and interprofessional and patient } \\
\text { relationships/communication in rural environments. } \\
\text { 3. Assess and evaluate pertinent health issues in rural America and, specifically, rural Illinois. } \\
\text { 4. Evaluate how larger, structural forces such as rural healthcare policy at the local, state, and national levels } \\
\text { may impact the health of individuals within rural geographical and ethnic populations. }\end{array}$ \\
\hline $\begin{array}{l}\text { Rural Family \& Community Healthcare II } \\
\text { Spring Semester - Year } 1\end{array}$ & $\begin{array}{l}\text { Upon completion, students will: } \\
\text { 1-4. Same as Fall Semester. } \\
\text { 5. Evaluate the acceptable roles and responsibilities of rural healthcare providers in maintaining the health and } \\
\text { well-being of individuals both within and outside the context of the exam room. This includes leadership } \\
\text { positions that impact rural health policy at the local, state, and national levels. }\end{array}$ \\
\hline $\begin{array}{l}\text { Rural Family \& Community Healthcare III } \\
\text { Fall Semester - Year } 2\end{array}$ & $\begin{array}{l}\text { Upon completion, students will: } \\
\text { 1. Apply the core concepts underlying the specialties of family and mental healthcare, including holistic patient } \\
\text { care, family context, continuity of care, patient/family education, and interprofessional and patient } \\
\text { relationships/communication in rural environments. } \\
\text { 2. Assess and evaluate the cultural, psychosocial, and behavioral dimensions of various clinical conditions } \\
\text { commonly encountered by healthcare providers in rural America and, specifically, rural Illinois. } \\
\text { 3. Evaluate the ethical and elderly issues associated with APN practice caring for individuals within rural } \\
\text { geographical and ethnic populations. } \\
\text { 4. Evaluate the acceptable roles and responsibilities of rural healthcare providers in maintaining the health and } \\
\text { well-being of individuals both within and outside the context of the exam room. This includes leadership } \\
\text { positions that impact rural health policy at the local, state, and national levels. } \\
\text { 5. Translate a basic knowledge of community oriented primary care into a working understanding of how this } \\
\text { can affect a desired change in the health status of a local rural populous. }\end{array}$ \\
\hline $\begin{array}{l}\text { Rural Family \& Community Healthcare IV } \\
\text { Spring Semester - Year } 2\end{array}$ & $\begin{array}{l}\text { Upon completion, students will: } \\
\text { 1-5. Same as Fall Semester in Year } 2 .\end{array}$ \\
\hline $\begin{array}{l}\text { Rural Family \& Community Healthcare V } \\
\text { Fall Semester - Year } 3\end{array}$ & $\begin{array}{l}\text { Upon completion, students will: } \\
\text { 1. Translate a basic knowledge of community oriented primary care into a working understanding of how: 1) an } \\
\text { Evidence Based Community Project can affect a desired change in the health status of a local rural populous and } \\
\text { 2) such efforts may be practically implemented. } \\
\text { 2. Identify and develop for implementation a rural community project that will be completed during the 4th year } \\
\text { DNP curriculum. } \\
\text { 3. Inspect and apply the role and activities of the Institutional Review Board (IRB) and the requirements for } \\
\text { conducting human research, evidence-based practice projects and quality assurance projects. } \\
\text { 4. Examine and apply the process of gathering and analyzing data used in rural community projects such as } \\
\text { using computers for managing patient data and accessing primary literature databases. } \\
\text { 5. Demonstrate knowledge, attitudes, and behaviors consistent with the Interprofessional Education } \\
\text { Collaborative (IPEC) designated four core competency domains needed for interprofessional collaborative } \\
\text { practice: interprofessional communication, understanding of roles and responsibilities, teamwork, and teams, } \\
\text { and understanding of values/ethics for interprofessional practice. }\end{array}$ \\
\hline $\begin{array}{l}\text { Rural Family \& Community Healthcare VI } \\
\text { Spring Semester - Year } 3\end{array}$ & $\begin{array}{l}\text { Upon completion, students will: } \\
\text { 1-5. Same as Fall Semester in Year } 3 .\end{array}$ \\
\hline $\begin{array}{l}\text { Issues in Rural IPC Practice I } \\
\text { Fall Semester - Year } 4\end{array}$ & $\begin{array}{l}\text { Upon completion, students will: } \\
\text { 1. Implement a rural community based interprofessional team project that will be completed during the 4th year } \\
\text { DNP curriculum. } \\
\text { 2. Examine and apply the integration of Telehealth services into Interprofessional Collaborative Rural Practice } \\
\text { to affect a desired change in the health status of a local rural populous and improve healthcare systems } \\
\text { improvement in rural settings. } \\
\text { 3. Demonstrate knowledge, attitudes, and behaviors consistent with the Interprofessional Education } \\
\text { Collaborative (IPEC) designated four core competency domains needed for interprofessional collaborative } \\
\text { practice: interprofessional communication, understanding of roles and responsibilities, teamwork, and teams, } \\
\text { and understanding of values/ethics for interprofessional practice. }\end{array}$ \\
\hline $\begin{array}{l}\text { Issues in Rural IPC Practice II } \\
\text { Spring Semester - Year } 4\end{array}$ & $\begin{array}{l}\text { Upon completion , students will: } \\
\text { 1. Evaluate and disseminate a rural community based interprofessional team project that will be completed } \\
\text { during the 4th year DNP curriculum. } \\
\text { 2-3. Same as Fall Semester in Year } 4 .\end{array}$ \\
\hline
\end{tabular}


Table 3. IPECC-SET 9 paired samples $t$-test, Year 1 and Year 2 nursing students

\begin{tabular}{|c|c|c|c|c|c|}
\hline $\begin{array}{l}\text { Variables for IPECC-SET } 9 \\
\text { Competencies }\end{array}$ & $\begin{array}{l}\text { Year } 1 \text { Mean } \\
\text { (SD) }\end{array}$ & $\begin{array}{l}\text { Year } 2 \\
\text { Mean (SD) }\end{array}$ & $\begin{array}{l}\text { Mean } \\
\text { Difference }\end{array}$ & $t$-score & $\begin{array}{l}p \text {-value } \\
<.05\end{array}$ \\
\hline $\begin{array}{l}\text { RR2: Recognize one’s limitations in skills, knowledge, and } \\
\text { abilities }\end{array}$ & $\begin{array}{l}88.944 \\
(18.367)\end{array}$ & $\begin{array}{l}88.500 \\
(4.949)\end{array}$ & 0.444 & 0.033 & .974 \\
\hline $\begin{array}{l}\text { CC2: Organize and communicate information with patients, } \\
\text { families, and team members that is understandable }\end{array}$ & $\begin{array}{l}90.500 \\
(12.444)\end{array}$ & $\begin{array}{l}88.000 \\
(16.971)\end{array}$ & 2.500 & 0.263 & .795 \\
\hline CC3: Express knowledge and opinions to team with confidence & $\begin{array}{l}87.632 \\
(17.892)\end{array}$ & $\begin{array}{l}86.250 \\
(5.560)\end{array}$ & 1.382 & 0.150 & .882 \\
\hline CC5: Prompt and respectful feedback to team members & $\begin{array}{l}82.684 \\
(19.299)\end{array}$ & $\begin{array}{l}85.000 \\
(10.133)\end{array}$ & -2.316 & -0.230 & .820 \\
\hline $\begin{array}{l}\text { CC7: Recognize one’s uniqueness contributes to effective } \\
\text { communication, conflict resolution and positive working } \\
\text { relationships }\end{array}$ & $\begin{array}{l}87.632 \\
(14.202)\end{array}$ & $\begin{array}{l}85.750 \\
(5.679)\end{array}$ & 1.882 & 0.257 & .800 \\
\hline $\begin{array}{l}\text { TT2: Develop consensus on ethical principles to guide patient } \\
\text { care and teamwork }\end{array}$ & $\begin{array}{l}85.778 \\
(16.289)\end{array}$ & $\begin{array}{l}89.000 \\
(15.556)\end{array}$ & -3.222 & -0.266 & .793 \\
\hline TT3: Engage other health professionals & $\begin{array}{l}81.944 \\
(20.907)\end{array}$ & $\begin{array}{l}84.250 \\
(4.425)\end{array}$ & -2.306 & -0.216 & .832 \\
\hline $\begin{array}{l}\text { TT7: Share accountability with other professions, patients and } \\
\text { communities for outcomes relevant to prevention \& healthcare }\end{array}$ & $\begin{array}{l}88.222 \\
(15.925)\end{array}$ & $\begin{array}{l}90.500 \\
(13.435)\end{array}$ & -2.278 & -0.193 & .849 \\
\hline TT11: Perform effectively on teams in a variety of settings & $\begin{array}{l}82.526 \\
(20.214)\end{array}$ & $\begin{array}{l}87.500 \\
(5.508)\end{array}$ & -4.974 & -0.480 & 636 \\
\hline
\end{tabular}

Table 4. Rural nursing courses evaluation data 2017-2021

\begin{tabular}{|c|c|c|c|c|}
\hline Courses/Semester & $\begin{array}{l}2017-2018 \\
\text { (1st Cohort) }\end{array}$ & $\begin{array}{l}2018-2019 \\
\text { (2 Cohorts) }\end{array}$ & $\begin{array}{l}2019-2020 \\
\text { (3 Cohorts) }\end{array}$ & $\begin{array}{l}2020-2021 \\
\text { (4 Cohorts) }\end{array}$ \\
\hline \multicolumn{5}{|c|}{ Rural Family \& Community Healthcare I \& II: } \\
\hline Fall & 4.50 & 4.80 & * & 4.67 \\
\hline Spring & 4.00 & * & 5.00 & $*$ \\
\hline \multicolumn{5}{|c|}{ Rural Family \& Community Healthcare III \& IV: } \\
\hline Fall & NA & 4.33 & * & * \\
\hline Spring & NA & * & * & 4.50 \\
\hline \multicolumn{5}{|c|}{ Rural Family \& Community Healthcare V \& VI: } \\
\hline Fall & NA & NA & * & * \\
\hline Spring & NA & NA & * & * \\
\hline \multicolumn{5}{|c|}{ Issues in Rural IPC Practice I \& II } \\
\hline Fall & NA & NA & NA & * \\
\hline Spring & NA & NA & NA & 5.00 \\
\hline
\end{tabular}

Note. Course Evaluation Scale: 5.00 (Excellent) to 1.00 (Poor), ${ }^{*}=$ indicates no results due to low responses, NA = course not offered yet

\section{Limitations}

While the RHP Programs include a combination of healthcare students from 3 different colleges, it was implemented at one institution. Thus, these findings may not be applicable to other universities. Expanded evaluation with further studies would be necessary to ascertain if the RHP Programs would be effective at another university. The learners themselves selected to participate in the RHP Programs on initial applications to the colleges with personal statements regarding interest in rural healthcare and interprofessional practice. Elimination of selection bias requires further investigation to examine the impact of IPEC pedagogy for learners in general health professional programs.

Additional, limitations include student attrition in the RHP programs. The RNURSING Program in particular, had a 56\% attrition rate. Follow up with these students revealed a variety of reasons external to the RHP Programs mostly related to work, family, school, life balance while attending school part-time and working fulltime. The RMED and RPHARM Programs enroll traditional fulltime students who do not maintain fulltime employment outside of the classroom resulting in a very low attrition rate (less than 5\%). The RNURSING Program is pursuing future scholarship 
opportunities from the Health Resources and Services Ad- ences and student program satisfaction, of those remaining ministration and the Illinois Farm Bureau to support the in the RNURSING Program, were not hindered by these nursing students and eliminate the financial need for them to limitations. work fulltime while attending school. The learning experi-

Table 5. Program evaluation: Qualitative RHP student survey responses on the benefits of the program sessions, courses and of the program overall

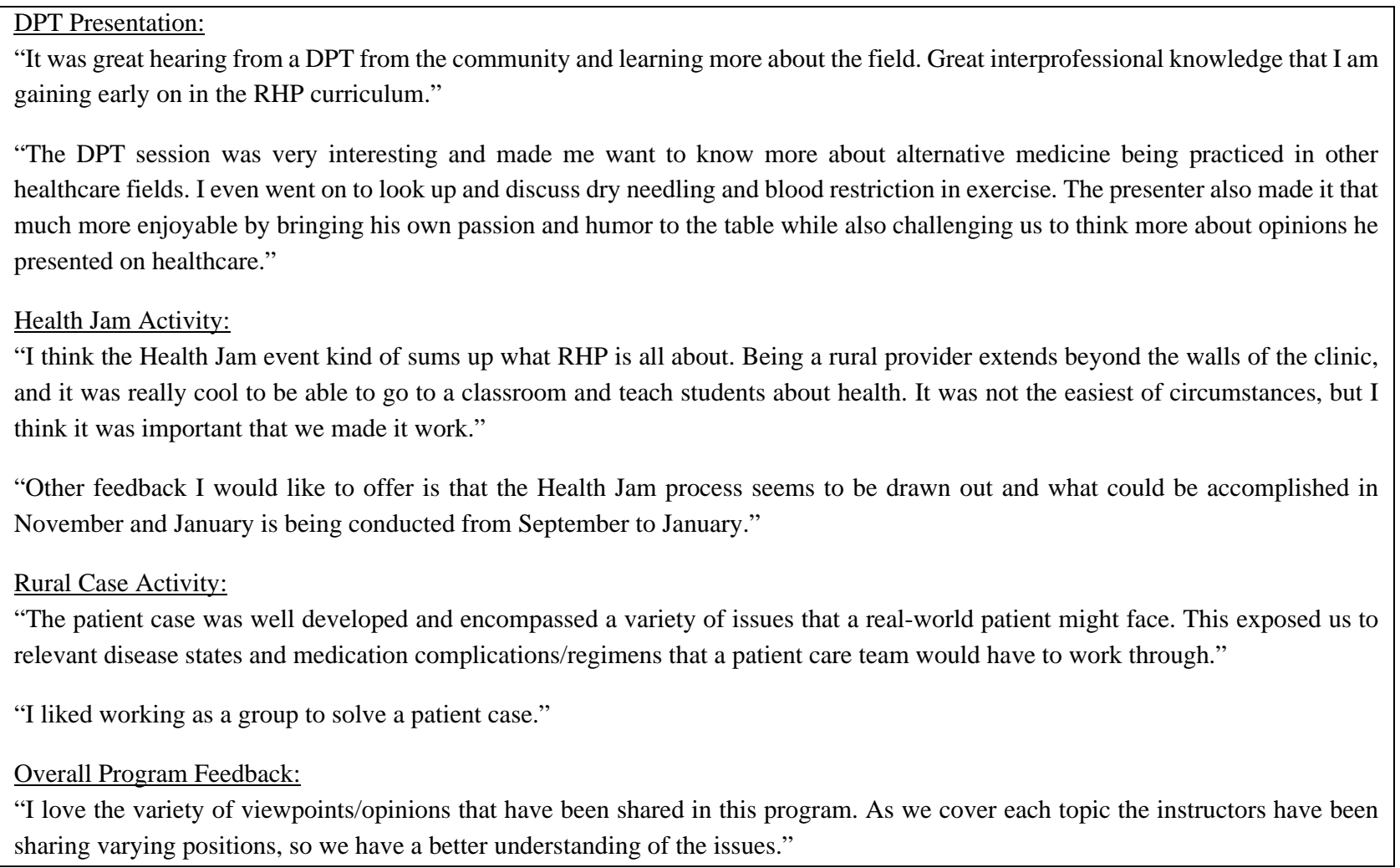

The student feedback for each activity is being utilized to tailor program refinements and quality improvements. Also, the course and program evaluation survey data will be utilized to identify additional areas for improvement. The RHP Programs meet essential requirements for health sciences colleges' accreditation and supports the IPEC practice model. The impact of the RHP Programs extends beyond the development and implementation of an IPEC practice curriculum. This preparation is fundamental for educating RHP students to be future members of the rural interprofessional healthcare workforce, trained to deliver inclusive and comprehensive family and patient-centered ethical healthcare. The RHP Programs support interprofessional, collaborative learning while preparing a rural healthcare workforce to function in effective teams, as advocates and leaders to enhance the well-being and healthcare of rural populations. The team of IP faculty are continually refining the RHP curriculum. Significant changes were made this year to respond to the educational and clinical challenges encountered during the COVID-19

Published by Sciedu Press pandemic with program activities being completed virtually.

\section{Conclusion}

The program's didactic and experiential learning activities as outlined were consistent with transformative learning principles. Utilizing transformative theory with students was an applicable pedagogy to develop ethical rural healthcare proficiency and attain competency for successful IPEC. Learners from three health sciences colleges benefitted from the program with confirmed satisfaction in interprofessional rural education and collaborative practice. Student evaluations demonstrated satisfaction with the rural health training program and the program included the four IPEC domains. The RHP Programs (RMED, RNURSING, and RPHARM) merit continuation with modification and expansion to prepare the future rural interprofessional healthcare workforce.

Future implications include formal assessment of demonstrated improvement in student's self-efficacy in rural healthcare proficiencies and competency in interprofessional team- 
work. The authors plan to continue to utilize the self-efficacy IPECC-SET tool created and validated by one of the authors along with other colleagues. ${ }^{[8,9]}$ Described by the Interprofessional Education Collaborative, each item in the IPECC-SET is founded on the fundamental competencies for interprofessional collaborative practice. ${ }^{[10,11]}$ The authors demonstrated an approach for assessing change in IP attitudes and competencies over time. However, a more robust/higher number of students being tracked over time with incentives to consistently respond to these surveys while in the RHP Programs are needed in future studies. Use of an assigned student ID would also help with the reliability of matching the data longitudinally since the students did not always recreate the code in items 1-4 consistently. In summary, the authors encountered several issues related to collecting longitudinal data and plan refinement moving forward with the expertise and collaboration of the fourth author and other colleagues who created and validated the IPECC-SETs.

\section{CONFlicts OF InTEREST Disclosure}

The authors declare that there is no conflict of interest.

\section{REFERENCES}

[1] Streeter RA, Zangaro GA, Chattopadhyay A. Perspectives: using results from HRSA's health workforce simulation model to examine the geography of primary care. Health Services Research. 2017; 52(S1): 481-507. PMid:28127767 https ://doi.org/10.1111/ 1475-6773. 12663

[2] U.S. Department of Agriculture. Economic Research Service. Racial and ethnic diversity is increasing in rural America. 2021. Available from: https://www.ers.usda.gov/webdocs/publications/ 44331/10597_page7.pdf?v=41055

[3] Taylor DCM, Hamdy H. Adult learning theories: implications for learning and teaching in medical education: AMEE Guide No. 83. Med Tech. 2013; 35(11): e1561-1572. PMid:24004029 https://doi.org/10.3109/0142159X.2013.828153

[4] Frenk J, Chen L, Bhutta ZA, et al. Health professionals for a new century: transforming education to strengthen health systems in an interdependent world. Lancet. 2010; 376(9756): 1923-1958. https : //doi.org/10.1016/S0140-6736(10)61854-5

[5] Kurt S. Kirkpatrick Model: Four Levels of Learning Evaluation. 2018. Available from: https://educationaltechnology.net/ kirkpatrick-model-four-levels-learning-evaluation/

[6] Archibald D, Trumpower D, MacDonald CJ. Validation of the interprofessional collaborative competency attainment survey (ICCAS), Journal of Interprofessional Care. 2014; 28(6): $553-$ 558. PMid:24828620 https://doi.org/10.3109/13561820.2 014.917407
[7] Schmitz CC, Radosevich DM, Jardine P, et al. The Interprofessional Collaborative Competency Attainment Survey (ICCAS): A replication validation study. Journal of Interprofessional Care. 2017; 1: 2834. PMid:27849422 https ://doi.org/10.1080/13561820. 201 6.1233096

[8] Hasnain M, Gruss V, Keehn M, et al. Development and validation of a tool to assess self-efficacy for competence in interprofessional collaborative practice. J Interprof Care. 2017; 31(2): 255262. PMid:28129012 https://doi.org/10.1080/13561820.2 016.1249789

[9] Kottorp A, Keehn M, Hasnain M, et al. Instrument refinement for measuring self-efficacy for competence in interprofessional collaborative practice development and psychometric analysis of IPECCSET 27 and IPECC-SET 9. J Interprof Care. 2019; 33(1): 4756. PMid:30156930 https : //doi.org/10.1080/13561820. 201 8.1513916

[10] Interprofessional Education Collaborative Expert Panel. Core competencies for interprofessional collaborative practice: report of an expert panel. In: Washington, D.C.: Interprofessional Education Collaborative. 2011. Available from: https://nebula.wsimg.c om/3ee8a4b5b5f7ab794c742b14601d5f23?AccessKeyId=DC 06780E69ED19E2B3A5\&disposition=0\&alloworigin=1

[11] Interprofessional Education Collaborative. Core competencies for interprofessional collaborative practice: 2016 update. Available from: https : //nebula.wsimg. com/2f68a39520b03336b41038c37 0497473?AccessKeyId=DC06780E69ED19E2B3A5\&dispositi on=0\&alloworigin=1 